Aziz-ud-Din Abmad 125

\title{
Comment:
}

\section{Census Problems in Pakistan}

\section{Aziz-ud-Din Ahmad}

The fifth decennial population Census was held after 17 years and its data is now being processed. Originally the Census was scheduled to be held in March 1991. The exercise had been actually initiated that year from Sindh but was soon abandoned when two major ethnic groups in the province started accusing each other of resorting to false enumeration in order to achieve a fake majority in the province. Some of the prominent Punjabi politicians also objected that the head count figures in Sindh were being engineered in order to stake claims to more resources for the province at the expense of other federal units. The Census was postponed in view of the objections and it was announced that the exercise would be undertaken in October the same year. This time the Balochistan government announced that it would reject the Census results if thousands of Afghan refugees living in the province, many among whom had acquired fake Pakistani identity cards, were not first repatriated to their own country. As the federal government failed to do this, the Census had to be postponed without any new date being fixed.

Thus for a total of seven years political reasons have continued to block the holding of a highly vital exercise without which economic planners are bound to be groping in the dark. Now that the Census has at last been conducted, it remains to be seen how accurate a picture of the population in various provinces it presents.

There was a boycott of the Census in certain Pakhtun areas of Balochistan on a call given by the Pakhtunkhwa Milli Awami Party (PKMAP) and the Pakhtun Ulusi Qaumi Jirga, which had demanded that instead of associating the army with the Census, the exercise should be overseen by a jirga of the Baloch and Pakhtun nationalities residing in the province. While the boycott was not effective, and the resistance to the head count had remained confined to a very limited area, census results of localities around Quetta were forcibly taken away from the census office by a group of armed men. How far all this has affected the results of the Census remains unclear. There are also problems created by illiteracy and cultural traditions. Complete registration of women, it has been claimed, does not generally take place because women are not conscious of the importance of registering themselves, while men, particularly those living in tribal areas, are reluctant to supply the information required about their womenfolk, or even to get them registered. 
A number of measures were taken by the government in order to discourage attempts at providing false information. Punishment for incorrect reporting was enhanced to sentence in jail up to six months, and a fine up to Rs. 1,500. Further, the army was deployed to assist the civilian enumerators in the hope that it would discourage attempts at disruption of the exercise or those aimed at engineering the numbers. There was also the provision of a recount if the census officials suspected that exaggerated enumeration on a considerable scale had taken place. There was also the provision of enforcing curfew in the area under dispute while conducting a fresh exercise. In spite of this, it remains doubtful if false reporting could have been stopped in areas where communities had been convinced they would suffer in case their rival ethnic group was to win the game of numbers.

In Pakistan, politics becomes associated with the Census for two reasons. First, the bigger a community, the greater is its representation in the Provincial as well as the Federal governments. Second, allocation of funds by the Federal government to provinces is made on the basis of their population, while the quota in Federal government jobs is also fixed on the basis of the population ratios of various provinces. As each province in the federation has a number of ethnic groups, there is also rivalry for political clout among them. In the Punjab, Seraikis and Punjabis; in Sindh, Mohajirs and Sindhis; in Balochistan, Pakhtuns and Balochis; and in NWFP, Pakhtun and a number of non-Pakhtun communities vie with each other for power that is based on numbers. In Sindh and Balochistan in particular the ethnic balance hangs by a thread, and the rival communities fear that they stand to lose in terms of economic benefits in case they lose in the head count.

In both Sindh and Balochistan, illegal immigrants can play a crucial role in determining the outcome of the Census. The government has failed to isolate them from the local population before the holding of the Census despite demands made by a number of political leaders. The failure has resulted essentially from the politics of alliances from which both the previous and the present ruling party have benefited. A large number of aliens have acquired false identity cards with the assistance of relatives, friends or political activists keen to enhance the number of their communities. Every year thousands of Indians visit relatives in Karachi and many of them destroy thair passports and claim Pakistani citizenship. As they speak Urdu, and belong to the same stock as many people living in Karachi, they get assimilated easily in the local population. Because getting a fake identity card is no problem in Pakistan, they soon acquire what the Census department regards as a genuine proof of citizenship. Exactly how many aliens of Indian origin have been registered will never be known. There would, however, be indications in the final census results to show their presence. Normally, the rate of increase in the Urdu speaking 
population of Karachi should be lower than the rate of increase in the rural Sindhi speaking population which has less propensity for family planning. In case the ratios were to violate this common sense projection, it would either be on account of inflated enumeration or because of adequate number of aliens having been registered as Pakistanis. The last Census had indeed led to an over-representation of the mohajir population in Sindh on account of a loaded question in the census questionnaire which had asked for the "language spoken at home" rather than the mother tongue. As most of the Punjabis and Sindhis living in Karachi happen to speak Urdu at home, they were wrongly included in the category of those whose mother tongue is Urdu, and consequently categorised as mohajirs.

In Balochistan, enumeration of Afghan refugees in the Census could lead to a misrepresentation of the ethnic position in the province. The local Pakhtuns have an ambivalent attitude towards these refugees. While the common man resents their continuous presence on account of rivalry in business and in sharing of the limited civic amenities, Pakhtun politicians want the Afghan refugees to be given the status of Pakistani citizens because this offers them an opportunity to inflate the numbers of their community, and lay claim to an equal, if not greater share in the province. It has been reported that while the PKMAP and the Ulusi Jirga were on the one hand issuing calls for the boycott of the Census, on the other hand they were encouraging maximum participation of the Pushtu speaking community in the Census.

The population of Punjab has over the last many censuses grown at a smaller rate than the population of other provinces because of comparatively greater migration from Punjab as well as on account of wider acceptance of family planning in the province. Politicians in Punjab have in the past expressed concern over the phenomenon because a genuine head count after seventeen years could lead to a not inconsiderable decrease in the representation of Punjab in the National Assembly. There is a fear in the smaller provinces that a genuine census might not be acceptable to Punjab and the results might be doctored in order to avert this unhappy outcome. This would not be easy to do though, because any significant deviation from the past census trends is bound to be widely questioned.

It has been suggested that the best way to have a genuine census is to delink the two issues of parliamentary representation and apportionment of development funds and job quotas from the census results. Seats in the Assemblies, it is argued, should be frozen at the present level for a number of years and development funds be distributed on the basis of need rather than population size, with the less developed regions receiving a bigger share of the cake than the more developed ones. As far as the quota in 
government jobs is concerned, with the ongoing downsizing, as well as reduction in the size of the government, these jobs are in any case going to be fewer than ever. India presents an example where, through a constitutional amendment in 1976, the Indian Parliament fixed membership of the Lok Sabba at 555, with the figures of the 1971 Census serving as the basis of representation, till the results of the first census after the year 2000 becomes available. In the peculiar situation of Pakistan, the suggestion creates two problems. First, it could be interpreted as an attempt on the part of the Punjab to safeguard its preponderant position in the National Assembly despite the reduction in its relative demographic position. The suggestion to freeze, for a particular time, the present number of National Assembly seats can in any case work only after a constitutional amendment has been passed. This can only be done when a consensus over the issue has been created between the different provinces. Only a government enjoying the confidence of all the federal units, and not identified with the interests of one province can hope to get the amendment through.

Secondly, the move to freeze the Assembly seats at their present level is bound to be seen as a move by the feudal lobby to retain its hold over the levers of state power. The fast rate of urbanisation in Pakistan, duly documented in succeeding census reports, will be reflected in the results of the present demographic survey also, replacing the preponderance of the rural population, the basis of the supremacy of the feudals in Pakistan's politics, with a balance between the rural and urban sides. By keeping the seats in the Assemblies at their present level, it will be argued, the feudals want to preserve their political domination.

There is no gainsaying the fact that allocation of funds to provinces on the basis of population rather than actual needs has resulted in a pattern of growth where less developed provinces have been forced to remain backward because they were smaller in population size. Again, it is no doubt irrational to provide roads to a province like Balochistan, commanding 43 per cent of the total land area of the country, on a per capita basis. It is also a fact that allocating development funds on the basis of actual needs instead of population is no novel idea in today's world. However, any move to delink allocation of resources from population ratio, prior to a consensus between the federal units, is bound to generate misgivings and would be difficult to carry in the Parliament unless an exercise of confidence building is conducted between the provinces prior to this. This requires leadership with a vision, not identified with narrow regional interests, and capable of winning over the trust of the people of Pakistan, irrespective of their ethnic backgrounds. 